\title{
EDITORIAL
}

\section{Information systems in psychiatry ${ }^{1}$}

For a century and a half there has teen statutory collection of mortality and hospital morbidity statistics. The procedure has remained essentially the same, with the main innovation teing the separation of first and subsequent admissions. Although hospital records often have contained detailed information on patients, traditionally only a few descriptive items have been reported by the hospitals to government. The data have been published annually in the familiar form of simple cross-tabulations tetween demographic features, diagnoses, individual hospitals and periods of stay.

As Shepherd (1957) and Richman (1966) have noted, mental hospital statistics have been put to good use in descriptive studies in the United States, Scandinavia and Britain. The figures were used by Goldhamer \& Marshall (1953), for example, to show that in Massachusetts the admission rate for the psychoses had been constant for the century starting in 1850 ; and their systematic reporting enabled Malzterg in New York (1952) and Ødegaard in Norway (1961) to undertake their monumental studies in mental hospitals. The slow passage of the insane through the mental hospitals and their causes of death were well monitored by these statutory information systems. So, while the mental hospital populations reached their peak in the mid-twentieth century, earlier statistics already had revealed altering discharge rates and lengths of stay (Shepherd, 1957).

Despite its demonstrated value, this massive information system has been roundly criticized. It pertains to events or groups of patients and not to individuals, the reliability of demographic and diagnostic data has keen uncertain, and the psychiatric information has not been linked with that from medical and social agencies. In reviewing the many government reports published in Britain, Maynard \& Tingle (1974) emphasized the limited amount of information published compared with that collected and noted that even elementary statistical manipulations have not been undertaken. Little (1975) reminded us that even serial censuses only afford a picture of usage of resources and not needs of people. It would seem then that, while the psychiatric morbidity statistics have been employed occasionally in the planning and evaluation of mental hospital statistics (Tooth \& Brooke, 1961 ; Lancet editorial, 1971), they have not been used routinely in their present form when decisions regarding the allocation of resources are made. It is known that there is lack of uniform methods of data collection (Brooke, 1963; Kramer, 1969), low reliability of assigned diagnosis (Babigian et al. 1965; Kendell, 1974) and varying descriptions of first admissions, psychiatric facilities and age groupings (Brooke, 1963; Kramer, 1969). Kramer (1976) has concluded that, since morbidity rates are influenced by so many nosocomial factors and not assessed systematically, the handicap for planners and evaluators can only be lifted by having special research units organize systematic and comparative morbidity statistics. Such units would necessarily obtain more accurate hospital morbidity rates, case fatality rates and population denominators.

To an extent, this has been undertaken by case registers, defined by Richman (1970) as 'systems whereby records from a specified set of psychiatric facilities are collected for individual persons from a defined population and accumulated over time'. They record all psychiatric cases in discrete geographical areas but require a stable population and data in a standard format, preferably collected by trained interviewers (Hailey, 1971; Hall et al. 1973). Following their success in cancer and tuberculosis, registers were recommended by the WHO Expert Committee on health statistics, although diagnosis and comprehensiveness of data were noted to be weak points in psychiatry. As a result, registers have been established in several countries. They aim to collect reliable information with protected confidentiality and provide sampling frames for incidence, prevalence and longitudinal

1 Address for correspondence: Dr M. R. Eastwood, Clarke Institute of Psychiatry, Measurement in Psychological Medicine Section, 250 College Street, Toronto, Ontario, Canada. 
studies. It is of the greatest importance that registers should shed light on the natural history of disease, identify high-risk groups and indicate how the psychiatric needs of the population are provided for. Nevertheless, Kramer (1969) has emphasized that the development and maintenance of registers is complicated, and Gardner \& Bahn (1971) suggest that registers do not have sufficient users to justify costs and that output tends to overwhelm the operators. Another serious handicap of registers is the limitation to specialist-treated illness which, in psychiatry, precludes that major proportion treated by general practitioners or other specialists. Thus, the incidence of anorexia nervosa deduced from case registers as around 1 per 100000 (Kendell et al. 1973) had to be radically changed to 1 per 200 (Crisp et al. 1976) when all medical referrals from a school population were studied. While registers have provided sampling frames, their limited geographical size and restriction to specialist care, together with population mobility, have diminished their value.

Alternatively, record linkage, described by Acheson (1968) as 'being concerned with integration of data about people, families and communities' may be employed. Computer technology now permits systematic linkage of certain classes of medical records for whole populations, providing prospective information on the person, family and community. Routinely collected government information may be linked by name, age and other demographic factors so that service usage by cohorts of patients may be examined. This approach was the method employed by the extremely influential Tooth \& Brooke study in England and Wales (1961) and those of Foster in New Zealand (1964) and Richman in Canada (1966). Such studies are not commonly or readily undertaken since they are laborious, tedious and not easily compared. For example, in Toronto, a cohort study was undertaken by Woogh et al. (1977) to clarify why psychiatric hospital readmissions appeared to have doubled in the 1960 s to form two-thirds of all admissions. As usual, these figures referred to events rather than individuals, so that 5 admissions could represent 5 patients or 1 patient having 5 admissions. The intention was to trace the subsequent readmissions of all first admissions to the Metropolitan Toronto hospitals in 1969. While the data for the hospitals could be amalgamated and linked, it was realized early that on the average $30 \%$ of so-called first admissions were misreported since individual hospitals often chose to ignore previous admissions elsewhere. This meant that after random sampling each patient's case record had to be checked for verification. This exacting study, however, showed that over a 4-year period $69 \%$ were not readmitted and only $8 \%$ were readmitted 3 or more times. It was not possible to make adequate temporal or international comparisons with previous cohort studies, to put the large-scale pattern of continuous psychiatric care into context, since different countries do not always share the same terminology or criteria.

The difficult and isolated nature of these studies could be relieved by routine central linkage of statutory health statistics. A balance must be struck between the amount and the reliability of the information collected. Only a small amount is essential, and the quality improves as the amount decreases. Massive information systems are beguilingly comprehensive but are frequently deficient in the critical need for reliability. In our present understanding of medical ecology, with the complex interplay of medical, psychiatric and social factors in clinical practice, it seems preferable for central linkage to unite all medical and even social services rather than concentrate on single specialities. In other words, a linked system based upon access to the records of individuals for clinical and research purposes, but available as grouped data for administrative analyses, would permit studies of changes over time, reliable estimates of incidence and prevalence, measures of treatment effectiveness, patterns of health care and manpower distribution, and could lead to better international studies if standard systems were established in several countries.

To link these records an identification number is required. A national unique lifetime personal identifier (NULPI), conferred at birth and adjustable on marriage, is already in use in Scandinavia, France and West Germany, and is advocated in North America. The United Kingdom is an exception in that, while a unique number was implemented during the Second World War for all citizens, the national health service number has had a limited function since. The number is usually some alphanumeric identifier convertible into computer integer representation. It has been hotly debated as to whether the number should be unique to health or a social insurance number linked to other data systems. The social insurance number has usually been adopted, but has been already linked to 
income tax and pension systems in several countries. In Sweden, property ownership also has been linked with a system which is then accessible to such government departments as the police and military. In the interests of confidentiality, a unique health number linking hospital, general practice and even social service information has considerable advantages.

It is worth noting that the type of health service influences data reporting. Clearly the efficiency of reporting is potentially greater in countries which have a fee for service rather than a salaried or capitation scheme, since income depends upon supplying information. The strength of such a linked information system lies not only in the accurate monitoring of the increasingly costly health services but also in the increased understanding of health needs. The weakness lies in the inherent problems of reliability, confidentiality and cost, although the last may te modified by subsequent savings due to increased efficiency. Reliability may be improved by regular and consistent training of staff, whose motivation is enhanced by awareness of the purposes and destination of the data, and by the collection of a small amount of data, which is then regularly checked. Confidentiality is a complex and highly sensitive issue but, in brief, access through an independent body, as recommended by Baldwin et al. (1976), for example, and access to limited levels of information according to professional status are means of maintaining individual confidentiality and allaying public disquiet.

Rather than mere repositories of information for administrators, computers may be regarded as tools for clinicians to foster efficiency and efficacy of clinical practice. Complex computer technology makes it easier to assemble information systems. Epidemiological, service utilization and outcome studies, of interest to clinicians and administrators alike, should be promoted by better use of statutory reported data linked by unique identifiers. Ongoing studies in psychiatry alone are important because of a need for detailed information on changing service demands stemming from present expectations of psychiatry, the reduction of mental hospital beds and provision of general hospital psychiatric beds and the early discharge policy. It may te argued that failure to develop a large-scale information system could leave us with a complex, arcane health service consuming the largest single proportion of the gross national product, and governed by largely fiscal and not clinical considerations.

M. R. EASTWOOD, H. M. R. MEIER AND C. M. WOOGH

\section{REFERENCES}

Acheson, E. D. (ed.) (1968). Record Linkage in Medicine. E. \& S. Livingstone: Edinburgh and London.

Babigian, H. M., Gardner, E. A., Miles, H. C. \& Romano, J. (1965). Diagnostic consistency and change in follow-up study of 1215 patients. American Journal of Psychiatry 121, 895-899.

Baldwin, J. A., Leff, J. \& Wing, J. K. (1976). Confidentiality of psychiatric data in medical information systems. British Journal of Psychiarry 128, 417-427.

Brooke, E. M. (1963). (National statistics in the epidemiology of mental illness, October 1969.) A Cohort Study of Patients first admitted to Mental Hospitals in 1954 and 1955. GRO studies on medical population subjects No. 18. HMSO: London.

Crisp, A. H., Palmer, R. L. \& Kalucy, R. S. (1976). How common is anorexia nervosa? A prevalence study. British Journal of Psychiatry 128, 549-554.

Foster, F. H. (1964). Cohort Study of First Admissions, 1962. Special Report no. 27, Department of Health Special Series, issued by the National Health Statistics Centre, Wellington, New Zealand: Mental Hospitals Admission and Release Data.

Gardner, E. A. \& Bahn, A. K. (1971). Automation and data processing in psychiatry. American Psychiatric Association Task Force Report.

Goldhamer, H. \& Marshall, A. (1953). Psychoses and Civilization. Glencoe Press: Illinois.
Hailey, A. M. (1971). Long-stay psychiatric in-patients: a study based on the Camberwell Register. Psychological Medicine 1, 128-142.

Hall, D. J., Robertson, N. C., Dorricott, N. \& Olley, P. (1973). Scottish case register: second phase. Journal of Chronic Diseases 26, 375-382.

Kendell, R. E. (1974). The stability of psychiatric diagnoses. British Journal of Psychiatry 124, 352-358.

Kendell, R. E., Hall, D. J., Hailey, A. \& Babigian, H. M. (1973). The epidemiology of anorexia nervosa. Psychological Medicine 3, 200-203.

Kramer, M. (1969). Applications of Mental Health Statistics. World Health Organization: Geneva.

Kramer, M. (1976). Issues in the development of statistical and epidemiological data for mental health services research. Psychological Medicine 6, 185-215.

Lancet (1971). Need for the mental hospital. Editorial (February 27) i, 438-439.

Little, J. C. (1975). Censuses of: A. Patients in mental illness hospitals in England and Wales. B. Mental illness day patients in England and Wales. British Journal of Psychiatry, News and Notes November, 9-11.

Malzberg, B. (1952). Rates of discharge and rates of mortality among first admissions to the New York civil state hospitals. Mental Hygiene 36, 618-638.

Maynard, A. \& Tingle, R. (1974). The mental health services: a review of the statistical sources and a critical assessment of their usefulness. British Journal of Psychiatry 124, 317-326. 
Ødegaard, Ø. (1961). Pattern of discharge and readmission in psychiatric hospitals in Norway, 1926-1955. Mental Hygiene 45, 185-193.

Richman, A. (1966). Long-stay patients in Canadian mental hospitals, 1955-1963. Canadian Medical Association Journal 95, 337-349.

Richman, A. (1970). The use of case-registers of psychiatric care in epidemiological research of mental disorders. In Psychiatric Epidemiology (ed. E. H. Hare and J. K. Wing), pp. 257-272. Oxford University Press: London.
Shepherd, M. (1957). A Study of the Major Psychoses in an English County, Maudsley Monograph no. 3. Oxford University Press: London.

Tooth, G. C. \& Brooke, E. M. (1961). Trends in the mental hospital population and their effect on future planning. Lancet i, 710-713.

Woogh, C. M., Meier, H. M. R. \& Eastwood, M. R. (1977) Psychiatric hospitalization in Ontario: the revolving door in perspective. Canadian Medical Association Journal 116, 876-881. 